\title{
IDÉIAS
}

\section{Os dois sistemas são bons: tradição comanda}

\section{L.G. Nascimento e Silva}

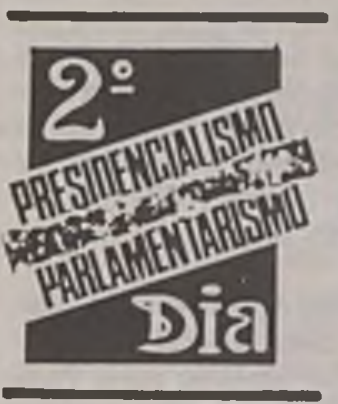

Dividem-se os regimes políticos das nações entre duas fórmulas de governo: o Parlamentarismo e o Presidencialismo, já que o regime de governo de diretório só se implantou na Suiça, além de suas experiências no Uruguai.

O Parlamentarismo nasceu e se desenvolveu, como se sabe, na Europa, onde no século XIII foram adotados os nomes de "Parlement" na França e de "Parliament" na Inglaterra, para designar a principio a reunião do conselho real ("curia regis"), e, mais tarde, uma permanente corte de justiça que se foi independentizando da autoridade real e passando a constituir um corpo de decisões que foram, cada vez mais, adquirindo vocalização para debate dos problemas de interesse geral, até virem a se converter no verdadeiro centro de decisão dos assuntos nacionais. Assim, o poder, antes enfeixado nas mãos do Rei, o soberano único, passou a ser exercido gradativamente pelo Parlamento com o Rei e, mais tarde, pelo Parlamento apenas, reservado ao Rei um papel meramente simbólico. E os Primeiros-Ministros são, hoje em dia, nos paises de governo parlamentar, os reais detentores do Poder Executivo.

Já a República, termo adotado primeiramente pelo governo da antiga Roma depois da expulsão dos reis etruscos, e mesmo anteriormente nas antigas cidadesEstado da Grécia, e mais tarde em certas cidades italianas da Renascença, como Veneza e Florença, ou na Inglaterra ao tempo de Crowell, veio a se consolidar como instituição ao final do século $\mathrm{XVIII}$, quando, com a revolta das treze

Luiz Gonzaga do Nascimento e Silva é advogado, ex ministro da Previdéncia Social, ex-embaixador brasileiro na França, pensador e humanista.

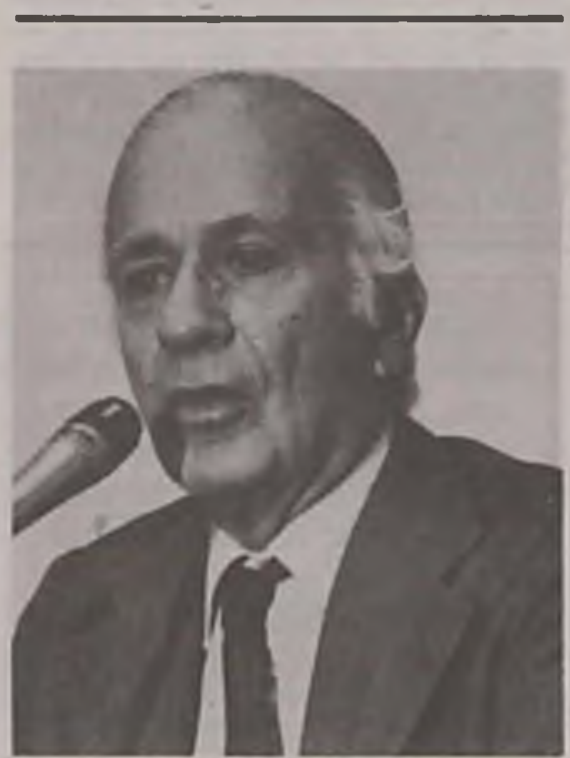

colônias da América do Norte, pôde surgir um pais independente, que se organizou como uma república.

Esses traços gerais das origens dos regimes Parlamentarista e Presidencialista já indicam as áreas principais da implantação de um e de outro, e as razões da subsistência de cada um deles por motivos históricos e de formação das respectivas idéias políticas.

Efetivamente os partidos políticos nos paises de regime parlamentarista conservaram principalmente uma ligação a tendências doutrinárias. $O$ modelo dos países de regime parlamentarista é, certamente, a Inglaterra. É que esse sistema conseguiu combinar a existência de um executivo forte e atuante com a realidade de um parlamento com fortes raizes populares. É que a tradição conta muito para o povo inglês, e há no país uma linha invariável de apoio ao regime parlamentar. $\mathrm{O}$ Gabinete, isto é, o Executivo, surgiu como um apêndice ao Conselho Privado, abrangendo os ocupantes dos principais cargos administrativos. Mais tarde, a indicação de seus componentes passou a ser atribuição do Primeiro-Ministro, que os escolhe por critérios vários, com predominância dos de sua experiência política. Mas o Primeiro-Ministro conserva uma preeminência indiscutida entre seus pares. De maneira formal diz-se que o Gabinete é responsável perante o Parlamento, mas na realidade a responsabilidade repousa mesmo no Primeiro-Ministro. É ele quem responde perante o Parlamento pelas decisōes tomadas.

Uma análise bastante crua da realidade constitucional inglesa foi feita pelo Ministro da Previdência Social britânico Richard Crossman nos registros de seu "Diário", postumamente publicado, em que afirma que "o Gabinete faz agora parte dos "majestosos" princípios da Constituição, no sentido de que as decisões efetivas são raramente adotadas nele, a menos que o Primeiro-Ministro decida deliberadamente dar a aparência de que o Gabjnete é que decidiu o assunto" " "The Crossman Diaries", pág. 92). Essa, afirma, Crossman, é a realidade nua e crua". O Primeiro-Ministro não é "primus inter pares", nada disso. Ele é o Primeiro Executivo em sua suprema autoridade" (pág. 97). Haveria, assim, na realidade, a atribuição dos mais amplos poderes executivos ao Gabinete, enfeixados esses poderes, porém, pelo Primeiro-Ministro.

O Gabinete inglês tem sido descrito como o pivô em torno do qual a maquinaria do sistema político se move. Não apenas executa e administra, mas toma as principais decisōes do pais, exercendo ainda a completa iniciativa nos assuntos fiscais e orçamentários. O Parlamento detém, é certo, os poderes nominais da legislação e da administração, mas na realidade é o Gabinete que os exerce, até que uma crise de confiança o deponha.

Outro país em que a evolução do parlamentarismo é de especial interesse é a França. Viveu ela sob a instabilidade política permanente a partir da Constituição de 1875. O regime parlamentarista que essa Constituição consagrava não dava ao Executivo a menor estabilidade. $O$ Presidente da República não tinha na realidade nenhum poder efetivo. Tão pouco o tinha o Gabinete, sujeito sempre ao po- 


\section{IDÉIAS}

der de dissolução pelo Parlamento. Pela multiplicação dos partidos políticos, jamais o Gabinete podia contar com uma maioria estável capaz de lhe dar estabilidade $\mathrm{O}$ Gabinete passou a ser efetivamente um agente do Parlamento, por ele nomeado livremente, como também revogável a seu bel-prazer. O que ocorreu foi, păradoxalmente, uma ausência de um parlamentarismo verdadeiro, pela inferioridade da situação do Chefe de Estado, e pela impossibilidade de apuração da responsabilidade ministerial, passando os Ministros a se considerarem apenas agentes do Parlamento nomeados e revogáveis por ele. Daí se ter formado uma generalizada ausência de responsabilidade. Mas, mesmo na sua função legislativa, o Parlamento se revelou ineficaz. A instabilidade da vida política contribuía para sua ineficácia no exercício da sua função primordial. Por isso houve afinal o recurso ao decreto-lei, pela necessidade de se conceder ao Poder Executivo meios eficazes de ação, mas mesmo esse processo se revelou como um recurso efêmero, que só tornava mais evidente o descrédito das instituições parlamentares.

Essa situação só foi solucionada pela entrada em vigor da Constituição de 1958 , concebida pelo General Charles De Gaulle que introduziu na organização constitucional francesa o poder efetivo da Presidência da República. Essa Constituição atribui ao Presidente o dever de velar pelo respeito à Constituiçào, como o de assegurar o funcionamento regular dos poderes públicos e a continuidade do Estado; torna-o o garantidor da independência nacional como da integridade do território e do respeito aos acordos da Comunidade e aos tratados (art. $5^{\circ}$ ). É ele quem nomeia o Primeiro-Ministro e o demite (art. $8^{\circ}$ ), nomeia os funcionários civis e militares do Estado (art. 13) à chefia do Exército (art. 15). E no artigo 16 ainda há uma disposição de importância fundamental: "Quando as instituições da República, a independência da Nação, a integridade de seu território ou a execução dos seus compromissos internacionais forem ameaçados de uma maneira grave e imediata, e o funcionamento regular dos poderes públicos constitucionais for interrompido, o Presidente da República toma as medidas exigidas por essas circunstâncias, após consulta oficial ao PrimeiroMinistro, aos Presidentes das Assembléias, assim como ao Conselho Constitucional. Ele informa a Nação por uma mensagem..."

Mas o Presidente não enfeixa todos os poderes políticos: a Constituição diz no

artigo 20 que é o Governo que determina e conduz a política da Nação. Ele dispõe da Administração e da força armada. E como "Governo" se entende o Primeiro-Ministro e o Gabinete de Ministros. O artigo 21 atribui ao Primeiro-Ministro toda a ação do Governo, a responsabilidade pela Defesa Nacional, a execução das leis e também a nomeação para cargos civis e militares. E o Parlamento-Assembléia Nacional e Senado enfeixam os poderes de legislar, e, de modo privativo, o de votar as leis (art. 34). É certo que esse artigo indica restritivamente qual será o domínio da lei: o que não esteja incluído nessa relação restrita, limitada, tem um caráter meramente regulamentar, diz o art.

\section{O Congresso não é apenas o centro da atividade legislativa, mas também o dos debates públicos, onde as várias tendências políticas e também administrativas acham uma sólida ressonância. \\ É o grande forum que vocaliza as diferentes correntes nacionais, e as converte em leis.}

37, e pode ser editado pelo Governo. $\mathrm{O}$ art. $38 \mathrm{da}$ Constituição dispõe ainda que - Governo, para execução de seu programa, possa solicitar ao Parlamento a autorização de adotar por "ordonnances", ou seja, por decretos executivos, durante periodos limitados, medidas que normalmente seriam do domínio da lei. Elas devem ser aprovadas em reunião do Conselho de Ministros, após consulta ao Conselho de Estado, submetidas à contra-assinatura do Chefe de Estado, e ratificadas pelo Parlamento. Finalmente o Conselho Constitucional vela pela regularidade da eleição do Presidente da República e, em caso de contestação, pela eleição de deputados e senadores, como pelas operações de referendo, pela conformidade à constituição das leis orgânicas e das leis que lhe sejam submetidas pelo Presidente da República, pelo Primeiro-Ministro, pelos Presidentes da Assembléia Nacional ou do Senado para exame de sua constitucionalidade (arts. 56 a 61). Uma lei declarada inconstitucional não pode ser promulgada, nem posta em execução (art. 62).

Vamos encontrar as razōes das modificaçōes adotadas pela Constituição fran- cesa de 1958 no discurso de De Gaulle em Bayeux em 1946 que esboça sua concepção da organização constitucional: em primeiro lugar, três poderes, Legislativo, Executivo e Judiciário, nitidamente separados e equilibrados; depois uma arbitragem nacional acima das contingências políticas e que assegure a continuidade; dai a criação de uma segunda assembléia o Senado - e de um Chefe de Estado, colocado acima dos partidos, com o encargo de velar pelo interesse geral, com a atribuição de nomear os ministros, dentre estes o Primeiro-Ministro, que dirigirá a política e a execução da administração; ao Presidente caberá ainda a função de servir de árbitro das questões nacionais, um chefe, encarnação suprema do interesse geral.

Como se vê não é possivel mais caracterizar o regime constitucional francês como um regime parlamentar puro. Presidencialismo e Parlamentarismo nele se mesclam de forma inexorável.

Vejamos agora como se implantou o Presidencialismo e quais são suas principais caracteristicas. Afora a adoção, por períodos mais ou menos curtos, de um Presidencialismo incipiente, é a partir da promulgação da Constituição americana de 1787 que devemos buscar os traços definitivos que vêm caracterizando o regime presidencialista adotado por inúmeras nações. Vamos encontrar, no "Federalist" $n$ : 39, que se deve creditar a Madison uma definição básica da república, que seria "o Governo que faz provir todos os seus poderes, direta ou indiretamente, da grande massa do povo e é administrado por pessoas que conservam seus cargos segundo a sua vontade, por um período limitado ou enquanto bem servirem. É essencial para esse governo que ele provenha da grande massa da sociedade... é necessário para tal governo que as pessoas que exerçam sua administração sejam nomeadas, seja direta, seja indiretamente, pelo povo". Eis uns traços gerais que são válidos ainda hoje para dar o contorno essencial da república.

Outra característica da república que se refletiu, primeiro na Constituição do Estado de Massachusets, e depois na Constituição dos Estados Unidos, é a da separação de poderes entre Legislativo, Executivo e Judiciário, sustentada por Montesquieu desde 1748 como essencial ao regime das liberdades: "Tudo seria perdido se o mesmo homem, ou o mesmo corpo de notáveis ou dos nobres, ou do povo exercesse esses três poderes: o de fazer as leis, o de executar as resoluções públicas e o de julgar os crimes e as dispu- 


\section{IDÉIAS}

tas dos particulares" ("Lesprit des lois, L. II, capitulo VI).

A verdade é que a separação de poderes é uma realidade fundamental na estrutura constitucional norte-americana. Cada um dos três poderes tem sua esfera de atuação bem delimitada, nenhum deles invadindo a área reservada aos outros.

o Congresso não é apenas o centro da atividade legislativa, mas também o dos debates públicos, onde as várias tendências políticas e administrativas encontram sólida ressonância. É o grande forum de debates que vocaliza as diversas correntes nacionais, que as discute e as converte em leis ou resoluções, ou indicaçōes para os rumos da vida nacional. É evidente que sua principal missão é a da legislação, mas esta não absorve as preocupações do Congresso e constitui apenas uma parcela de seu trabalho. A verdade é que o Congresso exerce diversas funções, além da de legislar: a representação, a construção de consenso, a do esclarecimento das linhas políticas, a dos debates sobre os grandes problemas nacionais, a da legitimação das políticas, a do que se rotula como "oversight", ou seja, a de que os programas legislativos seja obedecidos adequadamente pelo Executivo.

O Judiciário nos Estados Unidos adquiriu o "status" de um verdadeiro poder. Essa foi uma longa construção a partir do famoso processo Marbury versus Madison, em que o juiz Marshall afirmou que "o governo dos Estados Unidos se chama governo de leis, e não de homens". Certamente se tornaria ele indigno dessa altíssima denominação, se as leis não ministrassem recurso contra a violação de legitimos direitos adquiridos", e que "a teoria de que todo o governo, organizado por uma Constituição escrita, deve ser a de que é nula toda a resolução legislativa com ela (com a Constituição) incompativel". Assim, Marshall afirmou que os tribunais são os árbitros finais da defesa dos princípios da Constituição, o que the confere, portanto, poderes constitucionais eminentes: os da defesa da Constituição e também os de proferir as decisōes finais sobre qualquer problema legal do pais.

E, finalmente, o Executivo, investido no Presidente da República, abrange uma múltipla gama de altas atribuições, como as de Chefe de Estado, com a representação geral do País, recebendo e retribuindo as visitas de outros chefes de Estado e personalidades máximas em seus países, e participando de eventos de importância nacional, o que o faz o equivalente a um rei, mas também a um Primeiro-Ministro; o papel de um Chefe do Executivo, com a responsabilidade mais ampla do governo e da administração, assim como os poderes de nomear e remover milhares de servidores que constituem a camada superior da imensa administração pública, alguns com "o conselho e o consentimento do Senado", outros por decisão pessoal; exercer o cargo de "Comandante em Chefe do Exército e da Marinha dos Estados Unidos" e das milícias de vários Estados, quando chamados ao serviço do pais; cabe-lhe, nessas atribuições, por exemplo, conduzir e dirigir as pesquisas e desenvolvimento da aplicação de energia atômica, a decisão sobre a produção das bombas atómicas e outros materiais de fusão; dirigir a Comissão de Energia Atômica,

\begin{tabular}{c}
\hline O papel da burocracia é \\
essencial para o serviço \\
administrativo \\
público da nação, \\
e ela o tem exercido, seja nos \\
países de governo parlamentar, \\
seja nos de regime \\
presidencialista, com a \\
afirmação de seu grau de \\
independência. \\
Max Weber foi o primeiro a \\
analisar o fenômeno.
\end{tabular}

autorizando-a a entregar material físsil ou armas às forças armadas; permitir a prod'ç̧ão e a aquisição de qualquer material físsil (Decreto sobre Energia Elétrica, seção 6 (a); desempenhar as atribuições de Chefe da Diplomacia, partilhando com o Congresso e o Senado, este somente em aspectos especiais, cabendo ao Presidente as atribuiçōes exclusivas do governo no campo das relações internacionais, assim como a formulação da política e a condução dos negócios; essas atribuições passaram, nos dias de hoje, a serem as mais importantes e exaustivas para o Presidente; exerce ele ainda funções ligadas ao Poder Legislativo, cabendo-lhe guiar o Congresso em grande parte de uma atividade legislativa, desempenhando uma liderança em aspectos essenciais; informando o Congresso através dos "States of the Union" e the fornecendo informações sobre $o$ andamento da política mundial; ainda é ele o Chefe de seu Partido Político e o vocalizador dos anseios populares, através de mensagens na televisão, no rádio, nos jornais; e finalmente é ainda agora o Lider do Mundo Ocidental, cabendo-
The sugerir e conduzir uma decisão consertada entre as nações que se filiam à política ocidental.

O modelo da Constituição americana espalhou-se por toda a América e ainda em alguns países asiáticos, o que significa que as naçōes sem uma longa tradição monárquica, como sucede com os países europeus, encontram nos principios de organização republicana uma maior adequação às demandas da sua sociedade.

O certo é ainda que o primado absoluto conferido ao Poder Legislativo até a Primeira Guerra Mundial cedeu seu lugar ao Executivo forte e estável. As modificações profundas conseqüentes a esse grande conflito trouxeram ao mundo a afirmação da intrínseca necessidade do primado político do Poder Executivo. E nesse sentido o regime presidencialista, com a fórmula de um homem escolhido pelo povo, com a manutenção do mandato do Presidente por prazo certo, com uma mais efetiva separação de poderes entre Executivo e Legislativo, assegura melhor esse primado, evitanto as freqüentes crises que paralisam por periodos mais ou menos longos a presença e a atuação de um Executivo eficaz. Dai o surgimento de um sistema misto, como o proposto pela Constituição francesa de 1958, ainda que este não haja resolvido o problema de um possível conflito entre a Presidência, o Primeiro-Ministro e o Gabinete, propiciando uma incômoda e inefícaz "co-habitação", que acumula as divergências sem as solucionar.

Há alguns aspectos da organização constitucional que têm grande influência no exercicio do poder, seja nos países de organização parlamentarista, seja presidencialista, e que são a federação, a burocracia.

A Federação constitui um sistema de pluralismo territorial. As várias atividades do Estado são divididas entre o governo central e os estados-membros; os possíveis conflitos de jurisdição são afastados por algumas disposições constitucionais estatuindo a prevalência do poder nacional sobre o dos estados, como ocorreu com as Constituições alemã de 1871 , de Weimar, e de Bonn (art. 31), e da Îndia (art. 254). A Suíça é um bastião invariável do sistema federativo, mas a importânci: que se passou a atribuir nos anos iicientes a medidas econômicas, e mesmo politicas, de amplitude necessariamente nacionais, tem dirigido o país para uma maior centralização. Nos Estados Unidos, graças à influência do Juiz Marshall, a Corte Suprema firmou entre 1809 e 1823 o papel da preponderância do direito da 


\section{IDÉIAS}

União, pelo conceito dos "poderes implicitos", sustentando a expansão do poder federal sobre o direito dos Estados (decisão Mc Culloch v. Maryland). Essa decisão histórica afirmou o Presidente da República como o pilar do poder nacional.

A Federação, pela influência da Constituição americana, foi adotada nos Estados Unidos da América do Sul e Méxi$\mathrm{co}$, e pelos novos países tornados independentes, como Índia, Paquistão, Burma, Canadá e Austrália são igualmente de organização federativa: os Estados-membros mantêm sua importância na organização nacional. Também a União Soviética e os países europeus de sua órbita adotaram a organização federativa.

Apesar dessa expansão no mundo, a realidade atual é que os princípios do federalismo estão também abalados. Os sistemas fiscais, especialmente o do imposto de renda, arrecadam para a União recursos abundantes, e ela tem de redistribui-los aos Estados, o que significa de certa forma o abandono do sistema federativo e um maior domínio de poder central. O processo de industrialização também tornam obsoletas as barreiras estaduais. A industrialização se desenvolve igualmente em termos nacionais, enfraquecendo os laços federativos. O certo, porém, é que em nenhum país que adotou o regime federativo há pressões sérias para seu abandono.

Outro aspecto relevante que concorre para uma modificação das estruturas de poder é o da importância que a burocracia passou a exercer, inclusive influindo na tomada de decisões do governo, seja ele parlamentar ou presidencial. Max Weber foi o primeiro a examinar esse fenómeno novo, e que constitui uma etapa decisiva na tomada de decisões administrativas. Cada empregado exerce um emprego numa hierarquia de estatutos que constituem uma escala administrativa. Há uma verdadeira especialização entre os ocupantes das carreiras funcionais. Ele em regra é contratado ou nomeado por concurso, de provas ou de títulos, e começa uma carreira hierarquizada, sendo promovido de acordo com regras que anulam ou limitam o favorecimento. Sua indemissibilidade, salvo por faltas graves, dá-lhe uma grande margem de segurança. Essa indemissibilidade é uma contrapartida necessária às exigências da burocracia.

Este não é um aparelho a ser livremente manejado pelos políticos, mas sim centralizado para garantir uma coerência à Administração. Por que os políticos aceitam essa quase tutela da burocracia? Porque são os burocratas que sabem dar efe- tividade e coerência às decisões administrativas, e isso concorre para o aumento do poder deles, políticos.

Essa necessidade de aprimorar a Administração pública levou vários países a organizarem escolas de formação da alta burocracia, propiciando cursos de ensino das principais matérias que poderão habilitá-los aos serviços do Estado ou mesmo da iniciativa privada em organizaçōes que exercem atividades de primordial importância, como os grandes bancos e as grandes companhias que dominam largas faixas do mercado. A França, por exemplo, há muitos anos que organizou a École Nacionale d'Administration - "ENA", que tem fornecido pessoal

A inalterada escolha que
diversos países
fizeram ao longo
da História, de um ou de outro
desses sistemas, mostra
bem que
não há uma excelência do tipo
de governo. Um ou outro
melhor convêm a cada um dos
países de acordo com a sua
formação, sua tradição e
sociedade.

qualificado para exercer os cargos da alta burocracia e mesmo da vida política nacional.

O papel da burocracia é essencial para o serviço da administração pública da Nação, e ela o tem exercido seja nos paises de governo parlamentar, seja nos de regime presidencialista, com a afirmação de seu grau de independência.

Ao final desta já longa exposição é oportuno perguntar: Qual o melhor regime de governo: o parlamentarismo ou o presidencialismo? A inalterada escolha que os diversos paises fizeram, ao longo da história, de um ou de outro, mostra bem que não há uma excelência de tipo de governo: um ou outro melhor convêm a cada um dos países, de acordo com sua formação, sua tradição, o contorno de suas sociedades, o tipo de problemas que a nação deve enfrentar, enfim as mil e uma características de cada uma delas.

Agora, quanto ao Brasil, podemos nos perguntar: será conveniente a adoção de um regime parlamentar de governo, afastando-nos de uma quase centenária prática do presidencialismo? Parece-me que não, e isso por motivos vários que julgo serem de evidência solar.

Em primeiro lugar, porque o parlamentarismo repousa na existência de partidos estáveis, com um programa definido que englobe os problemas políticos-administrativos da Nação, dirigidos por políticos de militância permanente e apoiados por um grupo significativo e permanente de eleitores que aprovam as posiçōes partidárias, seus programas, suas reivindicações. Esses partidos podem ter uma origem ideológica ou não, mas devem sempre constituir uma mobilização de homens em torno de certas idéias ou programas e de determinados objetivos políticos.

Ora, os partidos políticos brasileiros, com poucas exceçōes, não apresentam essa característica de permanência de objetivos precisos, nem de programas definidos. É de crer, portanto, que, com a adoção do parlamentarismo, iremos passar por extensos períodos de instabilidade política e administrativa, com verdadeiros hiatos no exercício do poder. $\mathbf{A}$ ausência de um poder executivo, que se dará inevitavelmente nos momentos de crise parlamentar, importará a criação de vazios no poder, com graves conseqüências para a vida nacional. Foi o que sucedeu tantas vezes na França durante a sua longa vida parlamentar até a adoção da Constituição de 1946, que transferiu para a Presidência da República importantes esferas da vida política do país e deslocou para o campo dos regulamentos e, portanto, da decisão do Executivo, numerosas atribuiçōes.

Mas mesmo uma Presidência como a define a Constituição francesa de 1946 é inadequada para o Brasil, sendo certo, por outro lado, que a França atravessa agora um periodo de crise de poder pela coexistência de um Presidente de filiação partidária diversa da do Primeiro-Ministro e da maioria do Parlamento. Há uma manifesta dualidade de poderes que emperra a Administração e prejudica o progresso do pais. $E$ isso sucede em um país com desenvolvimento político e social muito diverso do nosso, cuja sociedade é toda alfabetizada e tem um nível de vida homogêneo, situação bem distinta da brasileira que apresenta tão grandes desigualdades sociais e culturais, e ainda com elevado número de analfabetos.

O problema central das nações que já atingiram um amplo desenvolvimento econômico, social e político é, pois, muito diferente do nosso. Nossa maior ênfase não deve estar apenas na politica par- 


\section{IDÉIAS}

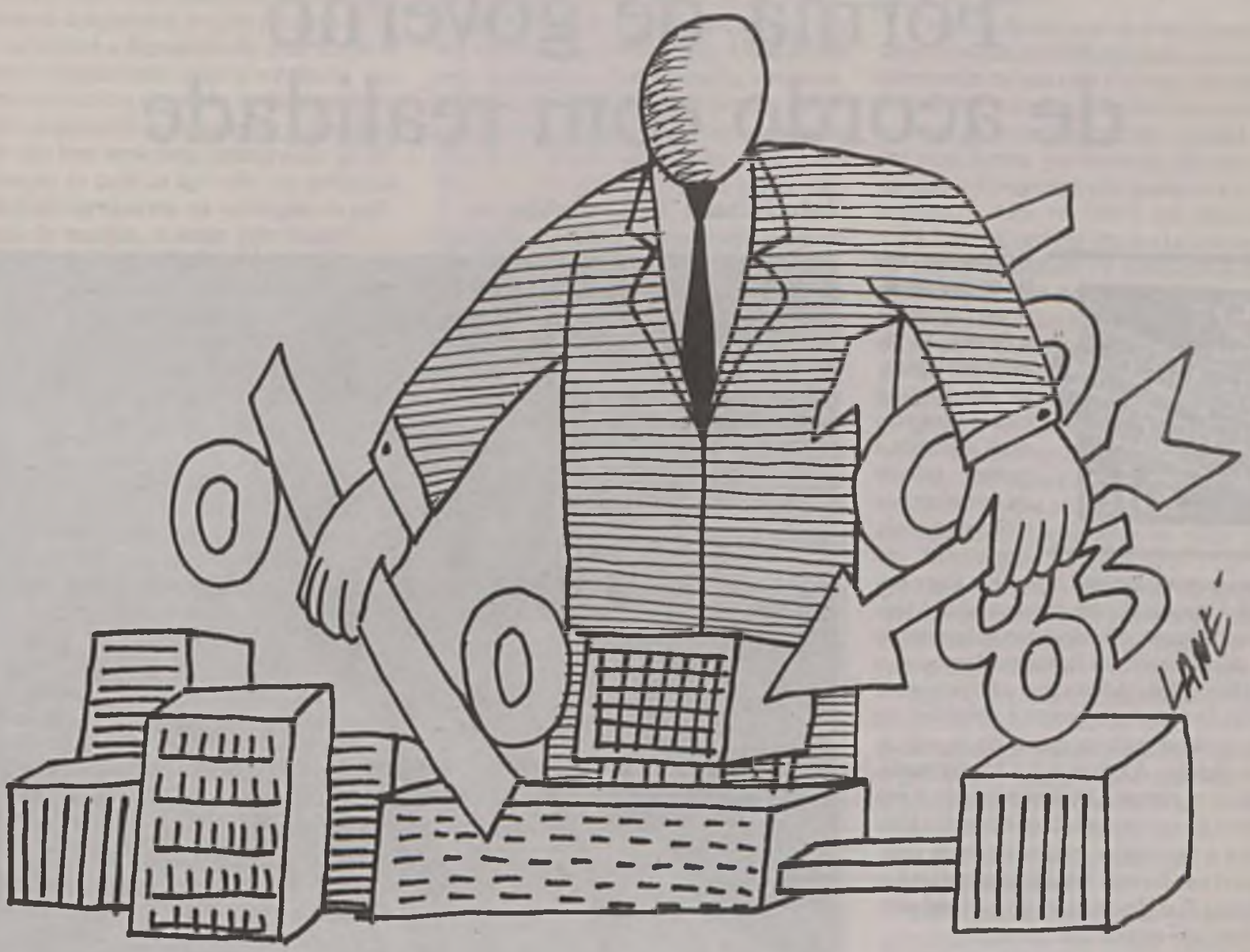

tidária, e sim no desenvolvimento econômico e social do país.

E o que contra-indica a adoção do parlamentarismo no país, e de modo especial no presente momento, é a necesidade que temos de manter fortalecida a Administração, dando-lhe uma autonomia em relação à política partidária. O Brasil precisa agora, mais do que nunca, de continuar a expansão de sua economia, prosseguindo e elaborando os grandes projetos de desenvolvimento nacional em vários setores, completando a malha das realizações que virão dar-lhe uma posição de destaque no plano da economia mundial, como indicam sua potencialidade e a capacidade de seu povo.

Ora, transferir o campo de realizaçōes econômicas do país do Poder Executivo para o Legislativo, o que sucederia fatalmente com a adoção do parlamentarismo, seria colocá-lo nas malhas da política partidária e, portanto, subordinar as decisōes, como sua execução, às pressōes dos par- tidos e dos grupos regionais. Não que se deva duvidar do patriotismo e do espírito público dos parlamentares, mas indubitavelmente há elos e vínculos que podem impor aos representantes deste ou daquele Estado, desta ou daquela região, uma posição menos conveniente no contexto geral. A decisão sobre os grandes projetos, como sobre programas econômicos de extensão, precisa ser feita a partir de uma visão nacional e não regional. Ora, é impossivel dissociarem-se os vínculos dos políticos partidários dessa sua ligação aos elos que os prendem à cidade, região ou Estado em que têm sua base política.

A verdade também é que a realização de uma obra de vulto, como seja a construção de uma usina hidroelétrica ou nuclear, ou a de uma grande rodovia exige longos e meticulosos estudos e planos que obviamente não se podem fazer no âmbito do Legislativo, que é antes um "forum" de debates do que um organismo destinado a fazer estudos e projetos. Daí a evidente vantagem de se manter na esfera do Executivo a realização de tais estudos e, naturalmente, sua decisão. E esta se faz, sem dúvida, mais adequadamente no âmbito do Executivo.

E nem se diga que a Administração se afaste tanto da política, porque, como acentuam J.R. Pennoch e D. Smith. "... os serviços da administração não se limitam a administrar, eles estão na origem da politica; eles elaboram decisões políticas particulares e incitam os funcionários a segui-las, e interpretam as linhas políticas por seu poder regulamentar. Por tais razões os rumos da Administração se encontram no centro da política propriamente dita" (Political Science. An Introduction", N.Y. Mac Millan, pág. 431).

Esses são apenas alguns aspectos irrecusáveis porque creio que a adoção do parlamentarismo, principalmente no atual momento nacional, trará ao país mais problemas do que soluçōes. 